\title{
UNE STATISTIQUE
}

\section{DE \\ LOCAUX AFFECTÉS À L'HABITATION \\ DANS LA ROME IMPÉRIALE \\ PAR}

M. ÉDOUARD GUQ

MEMBRE DE L'INSTITUT

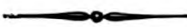

EXTRAIT

DES MÉMOIRES DE L'ACADÉMIE DES INSCRIPTIONS ET BELLES-LETTRES

TOME XL

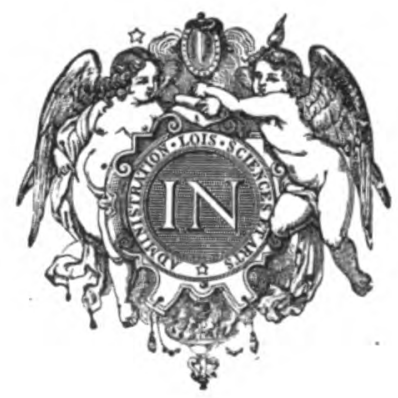

PARIS

IMPRIMERIE NATIONALE

LIBRAIRIE C. KLINCKSIECK, RUE DE LILLE, 11

MDCCCCXV 